\title{
Numerical Flow Simulation for Investigation of Changes in Energy Dissipation of Stepped Spillway Downstream in Stilling Basins
}

\author{
Akbar Dadras*1 and Mehdi Nejad-Naderi ${ }^{2}$ \\ ${ }^{1}$ Master's student in Civil Engineering of Water and Hydraulic Structures, Islamic Azad University, Iran \\ ${ }^{2}$ Department of Civil Engineering, Islamic Azad University, Iran
}

Submission:February 26, 2018; Published: April 26, 2018

*Corresponding author: Akbar Dadras, Master's student in Civil Engineering of Water and Hydraulic Structures, Tonekabon Branch, Islamic Azad University, Tonekabon, Iran, Email: Adadras24@gmail.com

\begin{abstract}
Unlike Ogee spillway, the type of flow on spillway and also the number of steps, etc. can contribute to development of scour hole in the stepped spillway. A part of flow energy transmitted by stepped spillway becomes dissipated by steps, and thus less kinetic energy will be obtained than Ogee spillway downstream. Therefore, the stilling basins with lower lengths are built in stepped spillway downstream. This issue was studied by an experimental model and a series of experimental data was obtained. This paper used this experimental data to perform numerical flow simulation and compare with experimental results using the Finite Volume Method (FVM) and Fluent software. The iso-velocity vector in the stepped spillway was obtained in an experimental model with discharge of $29.88 \mathrm{l} / \mathrm{s}$ indicating that the increased length of middle basins would increase the risk of scouring. Furthermore, the reduced distance of initial basins would decrease the flow velocity on the bed of basins.
\end{abstract}

Keywords: Scour; Stepped spillway; Hydraulic jump; Energy dissipation; Fluent software

\section{Introduction}

Estimation of local scour depth is one of the important issues which have always been considered by civil engineers in designing hydraulic structures that are built in rivers and waterways. Neglect of this issue may result in irreparable financial and physical damages. Stilling basin is one of the structures affecting the energy reduction in the tail water of hydraulic structures and it plays a significant role in stilling the outflow of structures by its structural additions and creation of hydraulic jumps. Bed roughness is one of the effective factors in energy dissipation, the hydraulic jump control, and scour depth reduction. This study is a numerical research on experimental model for investigating hydraulic jump on a rough bed with roughness related to the stepped spillway. An experimental model located in Hydraulic laboratory of Islamic Azad University of Khorramabad was used to study numerical simulation of an experimental model for effects of bed roughness and slope on hydraulic parameters of flow.

Shojaeian performed a numerical simulation of hydraulic jump in stilling basin of Namrud storage dam. In this research, the hydraulic jump phenomenon was simulated by the help of Fluent software using the standard and RNG models. First, two turbulence models were verified using measured data by Chanson and Chacherau in a laboratory flume for accurate prediction of hydraulic jump characteristics. According to conducted studies, the results of RNG turbulence model were better than the standard model. Afterwards, this model was used to simulate hydraulic jump in the physical model for stilling basin of Namrud storage dam. The measured values of pressure, velocity distribution, and water level profile were compared through laboratory measurement and they were matched with each other.

Hydraulic jump is the most common method for energy dissipation in downstream of spillways, gates and chutes. It is necessary to build stilling basin to control jump in downstream of these structures, so that all or part of hydraulic jump occurs in the basin. Stilling basin is a short section of a floored waterway and can control the hydraulic jump, reduce the jump length, and convert the kinetic to thermal energy. Dimensions of basin can be reduced be taking measures such as building blocks at the bottom of chute or intermediate blocks for further dissipation of kinetic energy in the jump area. Since blocks are directly exposed to high flow or energy, they need high stability under which their dimensions will be increased and sometimes they will be exposed to Cavitation. Bed roughness is one of the methods which can 


\section{Civil Engineering Research Journal}

be replaced by blocks. Due to the presence of bed roughness in a controlled volume, the input and output momentum will not be equal, and the output momentum will be less than the input momentum as much as the resistive force of roughness. Stilling basins are the suitable places for creation, control and restrain hydraulic jump in tailwater of hydraulic structures; and the blocks inside the basins direct jumping into basins and dissipate small amount of kinetic energy in the hydraulic jump, and thus increase the efficiency of stilling basins. The rough elements have been used on the bed of basins in recent years. Different researchers have studied the effect of roughness on increase in efficiency of stilling basins and reduction of hydraulic jump length [1-5].

Bed roughness can have riprap, sinusoidal waves, and trapezoidal, rectangular and triangular forms across the width of waterway. Numerous studies have been carried out on the effect of bed roughness on the hydraulic jump characteristics. According to initial results of experimental research on hydraulic jumps in rough beds, the created hydraulic jumps on rough beds are shorter than the smooth beds [6]. The supercritical flow in downstream gates needs shorter length on rough beds than the smooth ones [7]. According to results of studies, the bed roughness will decrease the secondary depth and length of jump; and this reduction depends on Froude number and relative roughness [8]. The amount of reduction in the hydraulic jump characteristics depends on the Froude number and relative roughness in addition to roughness unevenness parameter, so that the more roughness is unevenness, the more jump characteristics will be reduced [9]. In the presence of stilling basin with armor layers, the slope of rocks can play an essential role in the energy dissipation phenomenon [10].

According to conducted studies, the bed roughness is an effective factor in reducing the costs of energy dissipation of stilling basins; and most studies on the hydraulic jump are conducted on smooth beds or detached roughness, while there are too few studies on dense and coarse roughness. Therefore, all of tests are done on the stepped spillway bed in this research which investigates the effects of different discharge rates on hydraulic properties and energy dissipation. Finally, some results of this study are compared with other researchers' studies.

\section{Studied Structure}

Modeling is performed according to examination of experimental data obtained by Roshan et al. [11] (Figure 1) (Table 1).

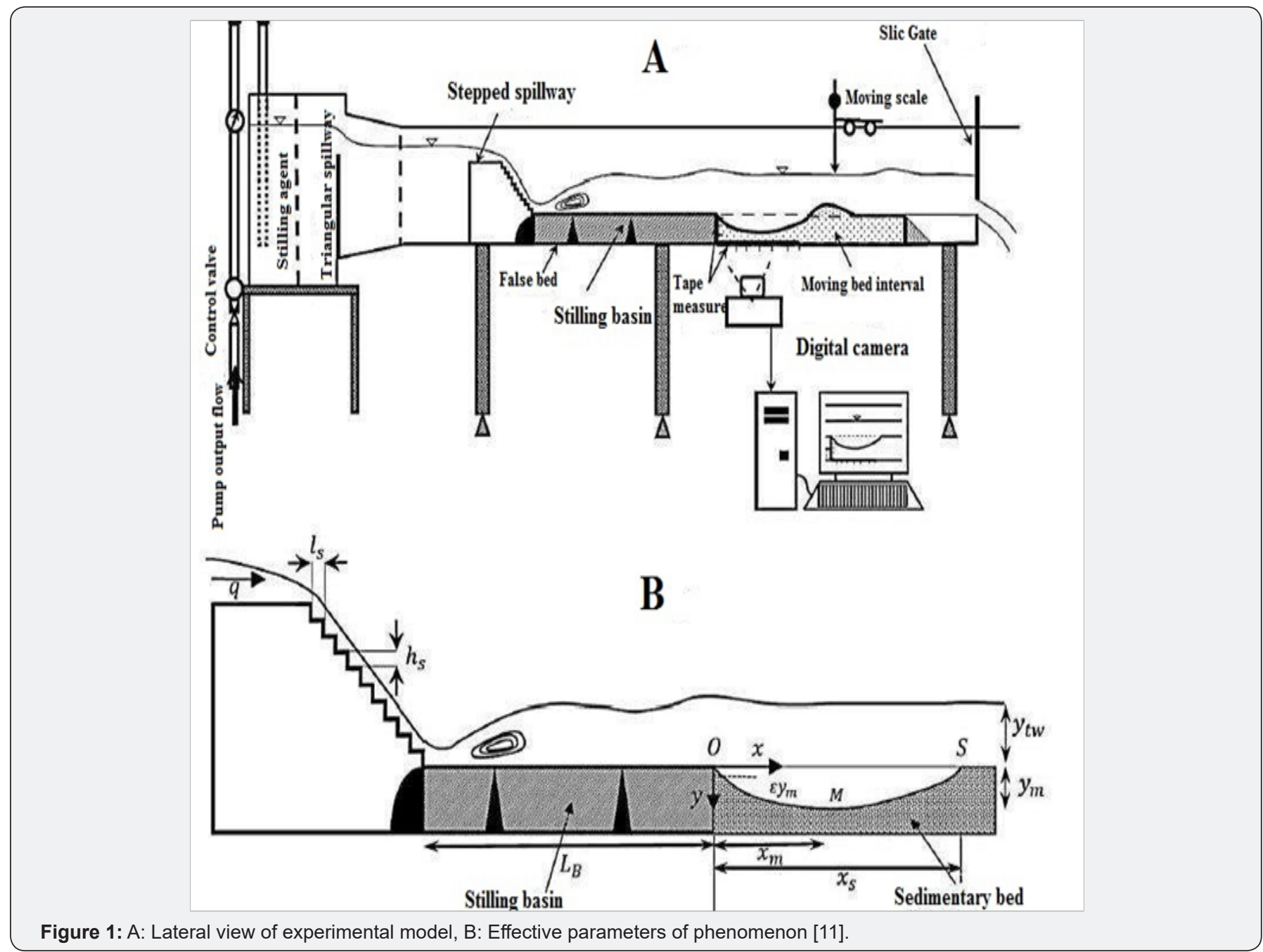




\section{Civil Engineering Research Journal}

Table 1: Domain of changes studied parameters [11].

\begin{tabular}{|c|c|c|}
\hline Parameter & \multicolumn{2}{|c|}{ Range of changes } \\
\hline & First Model & $31.518-88.951$ \\
\hline Discharge (l/s) & $7.43-29.888$ & $1.11,1.78$ \\
\hline Soil gradation & $0.58,1.11,1.78$ & 4 \\
\hline Height of step (cm) & 3 & 120 \\
\hline Length of step (cm) & 5 & 60 \\
\hline Length of stilling basin (cm) & $10,37,55,74$, and 110 & 90 \\
\hline Height of spillway (cm) & 45 & $11.63-21.71$ \\
\hline Width of flume (cm) & 41 & 12 \\
\hline Depth of tailwater $(\mathrm{cm})$ & $8.04-18.43$ & \\
\hline Number of tests & 55 & \\
\hline
\end{tabular}

\section{Modeling}

The geometry of spillway and stilling basis was first modeled in GAMBIT software, and then the boundary input and output conditions of flow were defined. Quad Element with Map type is used for plates, and Hex Element with Map type is applied for volumes (Figure $2 \& 3$ ).

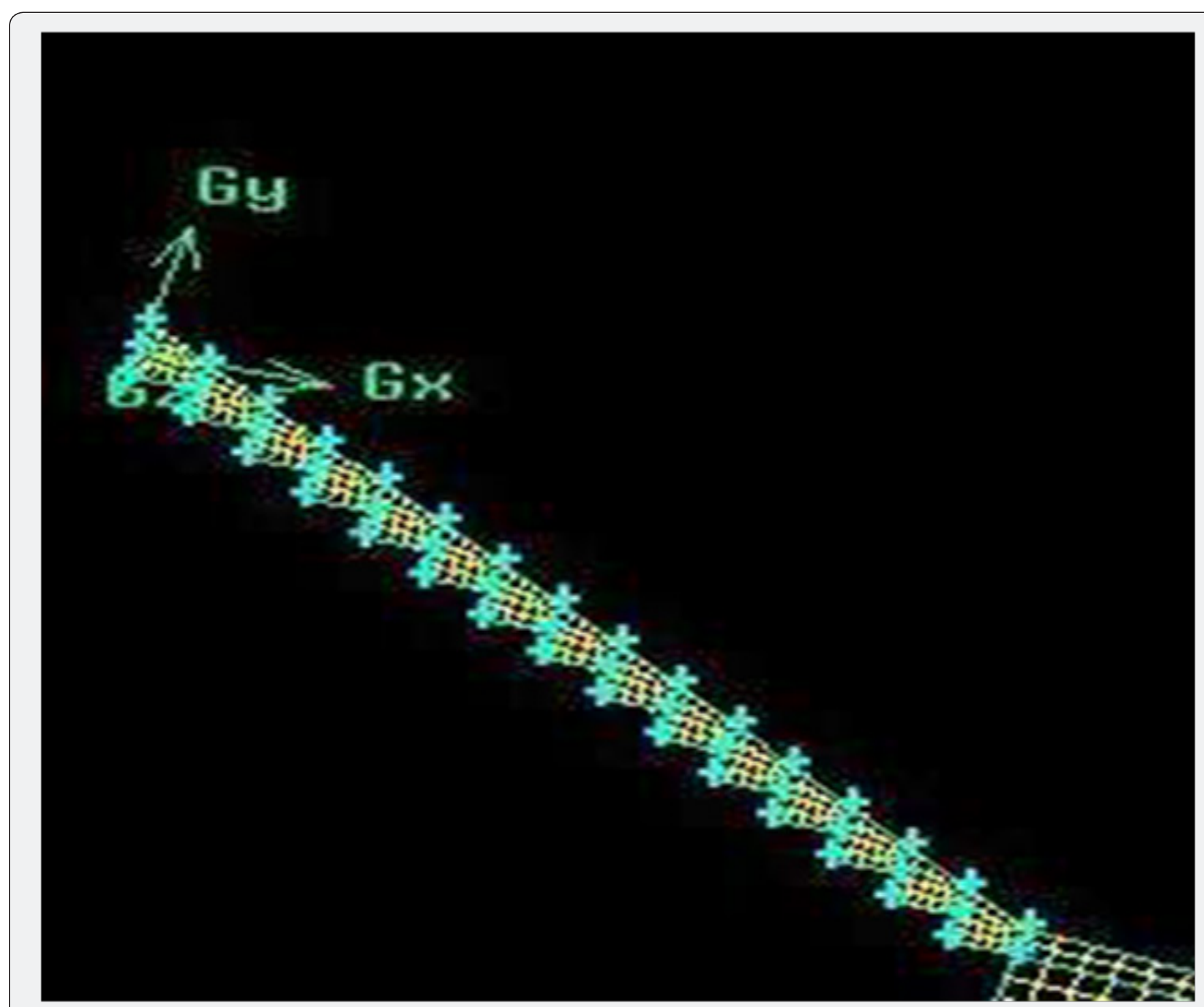

Figure 2: Meshing the stepped spillway model geometry with stilling basin. 


\section{Civil Engineering Research Journal}

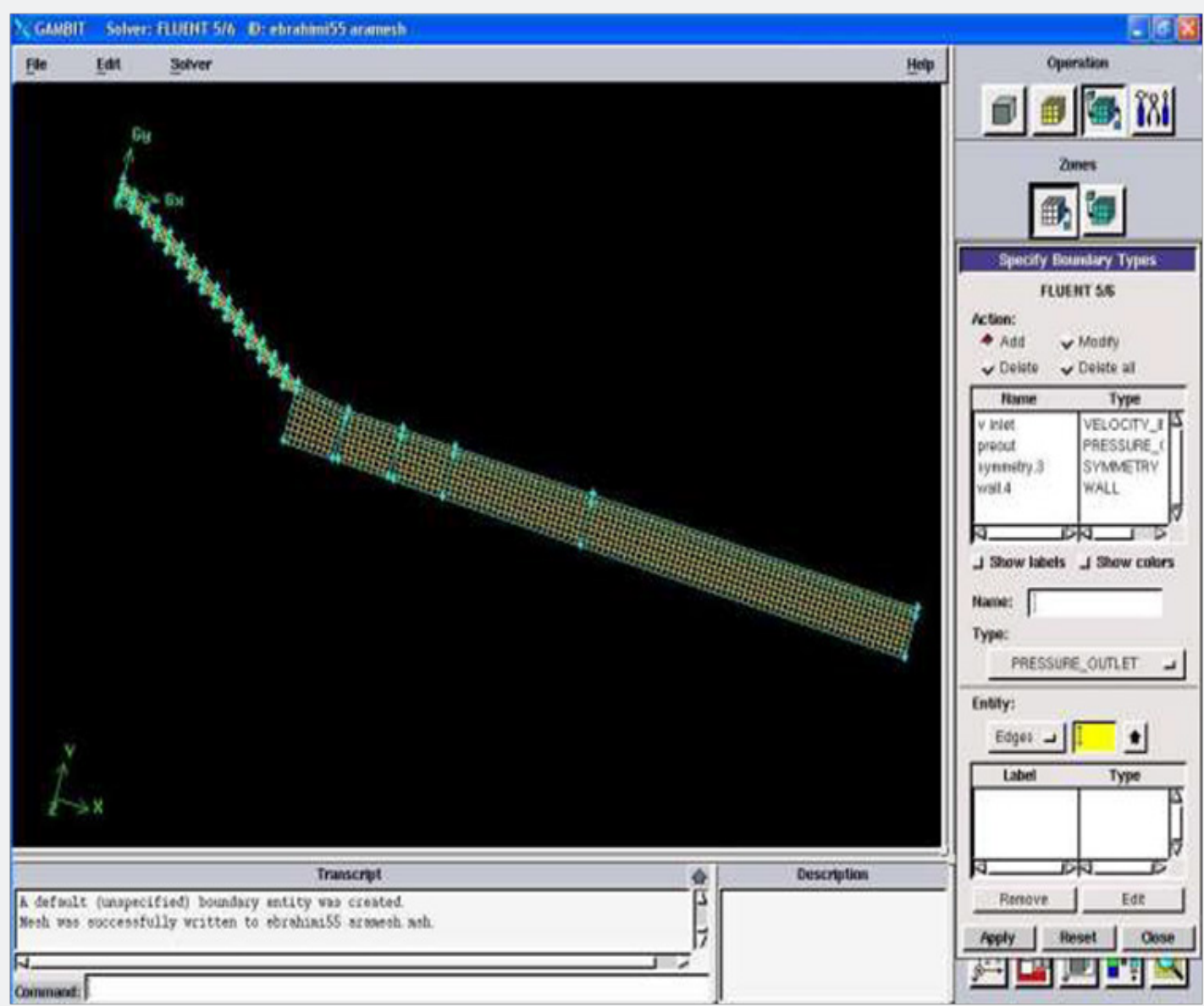

Figure 3: Meshing the stepped spillway model geometry with stilling basin with two rows of middle blocks and a length of basin equal to $55 \mathrm{~cm}$ in the experimental model.

\section{Numerical Simulation}

The obtained meshing was entered into Fluent software, and then the flow was analyzed by initialization of boundary conditions and selection of first-order solving models, and twoequation turbulence models. Results of analysis are presented in the following figures (Figure 4-6).

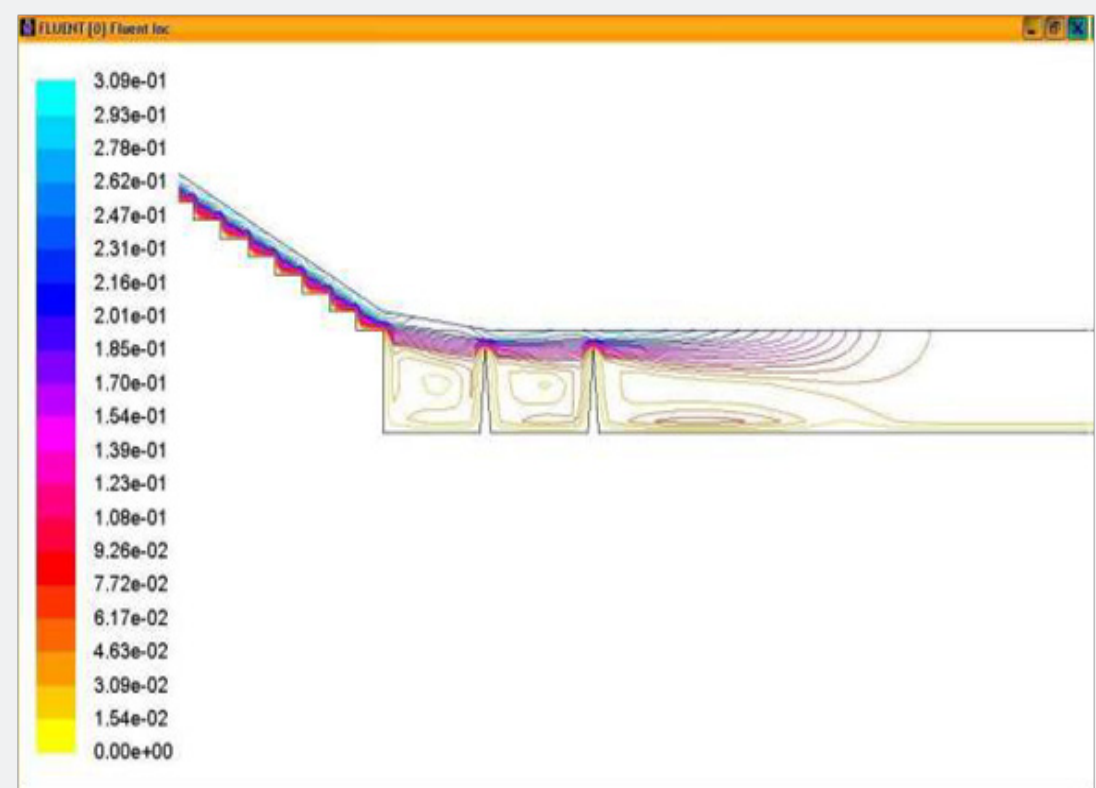

Figure 4: Iso-velocity lines in stilling basin at the length of initial basin equal to $55 \mathrm{~cm}$ in the experimental model; and the length of final basin equal to $120 \mathrm{~cm}$ in experimental model with discharge of $29.88 \mathrm{l} / \mathrm{s}$. 


\section{Civil Engineering Research Journal}

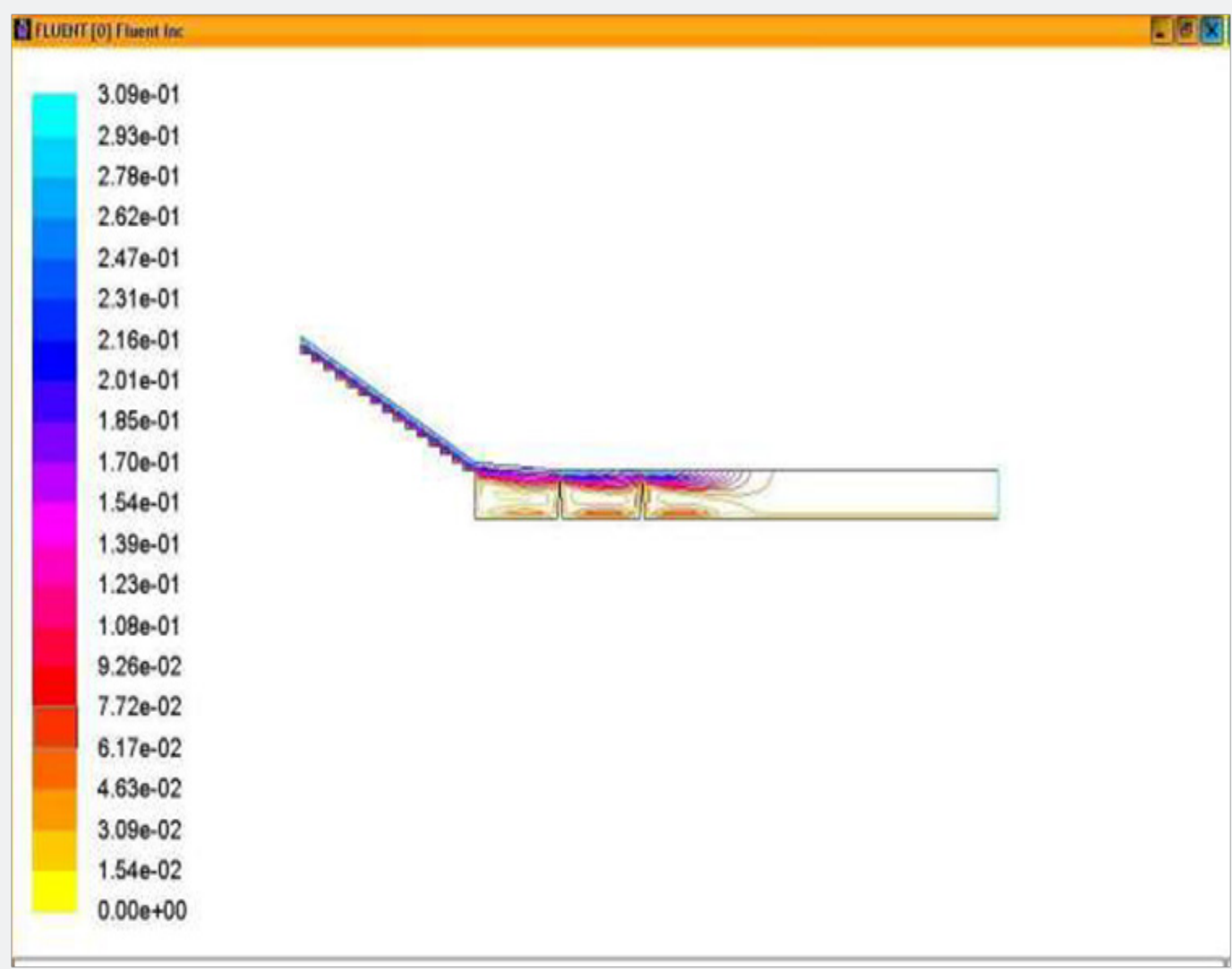

Figure 5: Iso-velocity lines in stilling basin at the length of initial basin equal to $110 \mathrm{~cm}$ in the experimental model; and the length of final basin equal to $120 \mathrm{~cm}$ in experimental model with discharge of $29.88 \mathrm{l} / \mathrm{s}$.

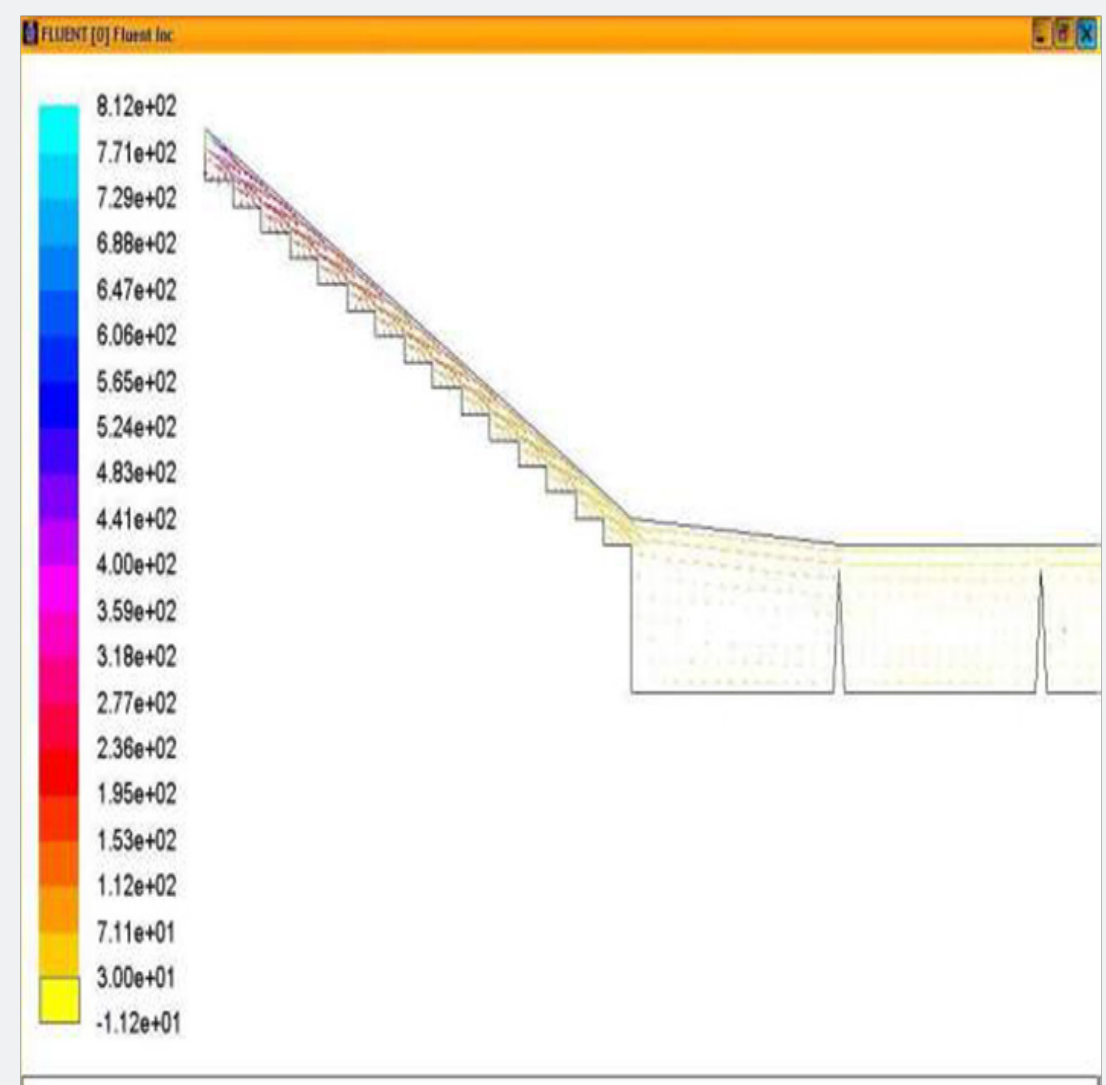

Figure 6: Iso-velocity lines in stilling basin at the length of initial basin equal to $110 \mathrm{~cm}$ in the experimental model; and the length of final basin equal to $120 \mathrm{~cm}$ in experimental model with discharge of $29.88 \mathrm{l} / \mathrm{s}$. 


\section{Civil Engineering Research Journal}

\section{Conclusion}

This paper used experimental data of stepped spillway for numerical flow simulation by the help of Finite Volume Method (FVM) and Fluent software. In the experimental model, the iso-velocity vector was obtained with discharge of $29.88 \mathrm{l} / \mathrm{s}$ indicating that the increased Froude number would increase scour depth. The scour profiles in the stepped spillway tailwater were investigated for two different flow regimes. According to results, the type of flow regime created on the stepped spillway was very important at the maximum scour depth. Therefore, the maximum scour depth in plunging flow regime was less than the non-plunging flow regime. Furthermore, the flow velocity would be reduced in the bed of basins by reducing distance of initial basins

\section{References}

1. Ead SA, Rajaratnam N (2002) Hydraulic jumps on corrugated bed. Hydraulic engineering 128(2): 656-663.

2. Rajartnam N (1968) Hydraulic Jumps on Rough bed, Trans. Engineering Inst. Canada 11(a-2): 1-8.

3. Gohari A, Farhoudi J (2009) The Characteristics of Hydraulic Jump on Rough Bed Stilling Basins. 33 IAHR Congress, Water Engineering for Sustainable Environment, Vancouver, British Columbia, p. 9-14.
4. Mohammad Ali HS (1991) Effect of Roughed Bed Stilling Basin on Length of Rectangular Hydraulic Jump. Journal of Hydraulic Engineering, ASCE 117(1): 83-93.

5. Tokyay ND (2005) Effect of Channel Bed Corrugations on Hydraulic Jumps. Impacts of Global Climates Change Conference, EWRI, May, Anchorage, Alaska, ASA, pp. 408-416.

6. Rajartnam N (1968) Hydraulic Jumps on Rough bed, Trans. Engineering Inst. Canada 11(a-2): 1-8.

7. Leutheusser HJ, Schiller EJ (1975) Hydraulic jump in a rough channel. Water Power and Dam Construction 27(5):186- 191.

8. Hughes WC, Flack JE (1984) Hydraulic jump properties over a rough bed. Journal of Hydraulic Engineering 110 (12): 1755-1771.

9. Pagliara S, Lotti I, Palermo M (2008) Hydraulic jump on rough bed of stream rehabilitation structures. Journal of Hydro-environment Research 2(1): 29-38.

10. Pagliara S, Palermo M (2012) Effect of stilling basin geometry on the dissipative process in presence of block ramps. Journal of Irrigation and drainage engineering 138(11).

11. Reza Roshan (2014) Study on local scour phenomenon in stilling basin downstream in the presence of stepped spillway; Scientificresearch journal 7(4).
This work is licensed under Creative

Commons Attribution 4.0 License

DOI: $10.19080 / C E R J .2018 .04 .555646$
Your next submission with Juniper Publishers will reach you the below assets

- Quality Editorial service

- Swift Peer Review

- Reprints availability

- E-prints Service

- Manuscript Podcast for convenient understanding

- Global attainment for your research

- Manuscript accessibility in different formats

( Pdf, E-pub, Full Text, Audio)

- Unceasing customer service

Track the below URL for one-step submission https://juniperpublishers.com/online-submission.php 